\title{
Factors affecting the development of airflow limitation among South Korean smokers
}

\author{
Youngmee Kim', Won-Kyung Cho
}

\begin{abstract}
INTRODUCTION Considering that only some and not all smokers develop chronic obstructive pulmonary disease (COPD), there may be other factors responsible for the development of COPD among smokers. Previous researchers have reported that ethnicity could be one of factors associated with the development of COPD. This study aimed to examine the factors associated with the development of airflow limitation, suggestive of having COPD, among Korean smokers using data from the Korea National Health and Nutrition Examination Survey conducted over the past 3 years.

METHODS A total of 2569 current and former smokers $\geq 40$ years of age were included. Most studies exploring risk factors for COPD have compared smokers and non-smokers with smoking as only one of the independent variables. In this study, we took a different approach, studying only smokers and comparing those with or without airflow limitation.

RESULTS The prevalence of airflow limitation among the study participants was $19.2 \%$ and $22.1 \%$ in current and former smokers, respectively. There was no significant correlation between the severity of airflow limitation and total lifetime smoking amount. Among the many variables examined, only age, male gender and total lifetime smoking amount (pack-years) were significant factors associated with the development of cigarette smoke-induced airflow limitation.

CONSLUSIONS Older Korean men who are heavy smokers may be at a higher risk of developing COPD. Our findings support the importance of smoking cessation as the best way to prevent the development of COPD.
\end{abstract}

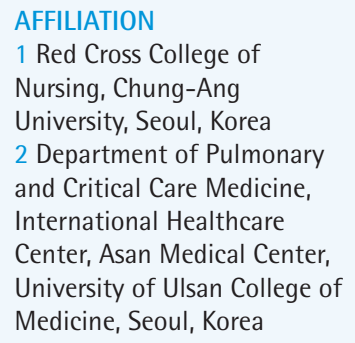

CORRESPONDENCE TO

Won-Kyung Cho. Department of Pulmonary and Critical Care Medicine, International Healthcare Center, Asan Medical Center, University of Ulsan College of Medicine, 88 Olympic-ro 43-gil, Songpa-gu, Seoul 05505, Korea. E-mail: wonkyungcho@hotmail.com

KEYWORDS

smokers, airflow limitation, Koreans

Received: 31 October 2018 Revised: 21 January 2019 Accepted: 21 January 2019

\section{INTRODUCTION}

Chronic obstructive pulmonary disease (COPD) is one of the leading causes of death worldwide. As of 2015, COPD affected about 174.5 million $(2.4 \%)$ of the global population ${ }^{1}$. Approximately three million people died of COPD in 2015, accounting for $5 \%$ of all deaths worldwide in that year ${ }^{2}$. By 2030 , COPD is expected to rank 4th on the list of causes of death and 7 th in terms of disease burden ${ }^{7}$. In Korea, the prevalence of cigarette smoking and COPD among adults in 2016 was $23.9 \%$ and $12.1 \%$, respectively. Due to its high prevalence, mortality and chronicity, COPD has been a global burden for many years. The
Global Initiative for Chronic Obstructive Lung Disease (GOLD), led by the National Heart, Lung, and Blood Institute (NHLBI) and the World Health Organization (WHO), defines COPD as 'a common, preventable and treatable disease that is characterised by persistent respiratory symptoms and airflow limitation that is due to airway and/or alveolar abnormalities usually caused by significant exposure to noxious particles or gases' ${ }^{3}$. Although environmental exposures such as air pollution, secondhand smoke and biomass smoke (e.g. animal dung and crop residues) and genetic factors may contribute to the development of COPD, smoking is predominantly the major 
cause $^{4-6}$. The risk attributable to active smoking in COPD has been reported to be $40-70 \%^{7}$. Previously, it was considered that only $15-20 \%$ of smokers develop clinically significant $\mathrm{COPD}^{8}$; however, recent studies have reported that about $50 \%$ of smokers eventually develop COPD during their lifetime ${ }^{9,10}$. Given that only some smokers develop COPD, it is important to identify the factors that may influence the development of COPD among smokers. It has been reported that various factors, such as aging ${ }^{11,12}$, gender ${ }^{13,14}$, abnormal lung growth and development ${ }^{5}$, occupational exposure to particles ${ }^{15}$, air pollution ${ }^{16}$, infection ${ }^{17}$, lower socioeconomic status ${ }^{18-20}$, nutrition ${ }^{21}$, obesity $^{22}$ and educational level ${ }^{23}$, were associated with a higher risk of developing cigarette smoke-induced COPD. Previous researchers have also reported that COPD risk varies according to ethnicity ${ }^{24,25}$. Therefore, some studies have examined the factors associated with COPD according to ethnicity or country; however, the risk factors identified were predominantly the same as those stated above $\mathrm{e}^{17,18,26-29}$.

The objectives of the present study were to examine the following: 1) the prevalence of airflow limitation among smokers, suggestive of COPD; 2) the factors associated with airflow limitation among smokers, and 3) the relationship between smoking history and severity of airflow limitation. To address these, we analysed the data from the Korea National Health and Nutrition Examination Survey (KNHANES). The KNHANES is an ongoing, nationally representative, annual cross-sectional survey compiling health data of the civilian population in South Korea ${ }^{30}$.

\section{METHODS}

\section{Data source and collection}

The present study was a secondary data analysis of KNHANES data from 2010 to 2012 (the fifth survey) conducted by the Korea Centers for Disease Control and Prevention (KCDC). Since the inclusion and exclusion criteria for this study required chest $\mathrm{x}$-ray data, as described below, only the fifth survey data that included chest $x$-ray information were used. The KNHANES consists of a health interview survey, a health examination survey and a nutritional survey. To minimise sampling bias, the KNHANES used a complex, stratified multistage probability cluster sampling design based on regional areas, sex and age. Further information about the study design and sampling process are provided elsewhere ${ }^{30}$. A total of 24173 individuals participated in the fifth (2010-2012) KNHANES survey. From among them, individuals who had undergone spirometry and smoked at least 100 cigarettes in their lifetime, regardless of current smoking status ${ }^{31,32}$, were included in the analysis. Records of individuals were excluded from the study if they: had never smoked or had smoked fewer than 100 cigarettes in their lifetime; had abnormal CXR findings due to lung diseases other than COPD as confirmed by a radiologist; had a history of other pulmonary diseases such as asthma, sarcoidosis, pulmonary tuberculosis, lung cancer or interstitial lung disease; and those who had a forced expiratory volume in $1 \mathrm{~s}\left(\mathrm{FEV}_{1}\right) /$ forced vital capacity (FVC) ratio $\geq 0.7$ with $<80 \%$ of FVC to exclude the participants with restrictive lung disease ${ }^{33}$. Because spirometry was performed in individuals $\geq 40$ years of age in the survey, individuals $\geq 40$ years of age were included in this study. Therefore, a total of 2569 participants were included in this study. Figure 1 demonstrates the selection process and the number of study participants.

\section{Figure 1. Flow diagram showing inclusion and} exclusion of studies

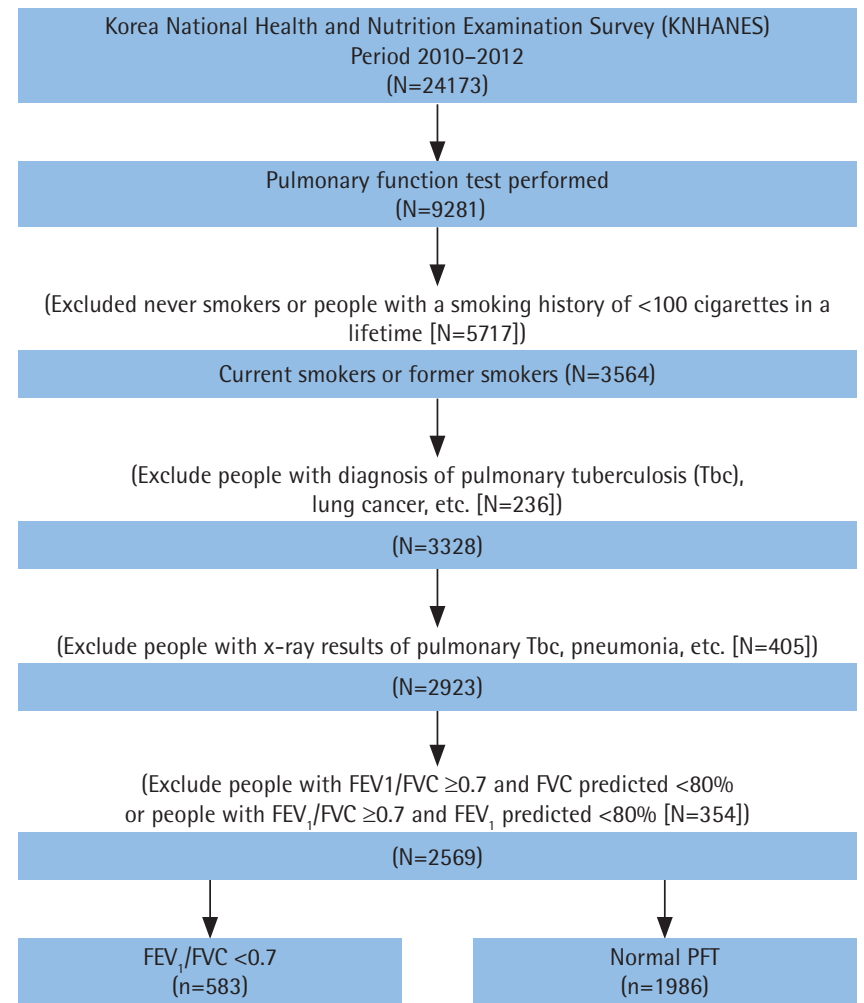




\section{Measures}

Spirometry

Spirometry was performed according to the acceptability and repeatability criteria published by the American Thoracic Society. The largest FVC and $\mathrm{FEV}_{1}$ were used for analysis after completing at least three acceptable adjustments ${ }^{34}$. The difference in FVC between the largest and next largest adjustments should be within $5 \%$ or $150 \mathrm{~mL}$ of each other, whichever is greater. If not, additional trials were made to meet the repeatability criteria ${ }^{34}$. The predicted value for each individual was determined using the reference equations derived from the Korean population ${ }^{35}$. Airflow limitation is defined by $\mathrm{FEV}_{1} / \mathrm{FVC}$ ratio $<0.70$, according to the GOLD guidelines $^{33}$. Airflow limitation that is only partially reversible with a bronchodilator or is completely irreversible is the characteristic physiological feature of COPD ${ }^{33,36}$. Therefore, both pre- and postbronchodilator spirometry data are needed to diagnose COPD. However, only pre-bronchodilator spirometry data were available for this study. The severity of airflow limitation is determined by the per cent predicted value of $\mathrm{FEV}_{1}$, thus the ranges $\mathrm{FEV}_{1} \geq 80 \%$, $50 \% \leq \mathrm{FEV}_{1}<80 \%, 30 \% \leq \mathrm{FEV}_{1}<50 \%$ and $30 \%<\mathrm{FEV}_{1}$ are observed in patients with mild, moderate, severe, and very severe airflow limitation, respectively ${ }^{33,34}$.

\section{Clinical diseases}

Diabetes mellitus (DM) was defined as a fasting blood glucose level $\geq 126 \mathrm{mg} / \mathrm{dL}$, taking oral hypoglycaemic agents or insulin injection or having been diagnosed with DM. Hypertension was defined as a systolic blood pressure $\geq 140 \mathrm{mmHg}$, a diastolic blood pressure $\geq 90$ $\mathrm{mmHg}$ or taking antihypertensive medications. Other diseases were defined based on a participant's medical history $^{30}$.

\section{Health behaviours, perceived health status and mental health}

The definition of smokers in our study was based on the guidelines of the Centers for Disease Control and Prevention (CDC): non-smokers were those who smoked $<100$ cigarettes in their lifetime, current smokers were those who smoked $\geq 100$ cigarettes in their lifetime and were current smokers at the time of the survey, and ex-smokers were those who smoked $>100$ cigarettes in their lifetime but quit smoking at the time of the survey ${ }^{31,32}$. Lifetime smoking amount (pack-years) was calculated by multiplying the number of packs of cigarettes smoked per day by the number of years the person smoked. Alcohol drinking was defined as the consumption of more than seven glasses of alcoholic drink per occasion, more than two times per week. Regular exercise was defined as a moderate level of physical exercise for $\geq 30$ min at a time $\geq 5$ times per week ${ }^{30}$. Perceived health status was categorised into different groups very good/good, fair or poor/very poor by self-rated levels of health status. Health-related quality of life (HRQoL) was evaluated using the EuroQoL ${ }^{37}$. The EuroQoL measures both a health-status descriptive system (EQ-5D) and a visual analogue scale (EQVAS), and ranges from 0 to 100 , where zero signifies worst health condition and 100 designates best health condition $^{37}$. Stress was defined as stress perceived to be moderate to severe. Depressive symptoms were defined as feelings of sadness disruptive to one's activities of daily living for at least two consecutive weeks in the past year. Suicidal ideation was defined as intention of committing suicide during the past year ${ }^{30}$.

\section{Statistical analysis}

All data were analysed using SAS version 9.3 (SAS Institute Inc., NC, USA); $<<0.05$ was considered to be statistically significant. The data are presented as mean \pm standard error (SE) for continuous variables or proportions for categorical variables. T-tests, ANOVA and $\chi^{2}$ tests were performed to evaluate the differences among the groups for continuous and categorical variables, respectively. Multiple logistic regression analyses were performed to explore the associations between airflow limitation and various factors. Variables that were statistically significant in the univariate tests were selected for the multivariate analyses. The results were reported using adjusted odd ratios (ORs) and their 95\% confidential interval (CI). A 95\% CI that did not span 1.0 was considered to be statistically significant.

\section{RESULTS}

\section{Prevalence of airflow limitation and mean ages of the study participants}

Table 1 summarise the prevalence of airflow limitation and mean ages of the study participants according 
Table 1. Prevalence of airflow limitation and mean age (years) among the study participants (current and former smokers)

\begin{tabular}{|c|c|c|c|c|c|}
\hline \multirow[b]{3}{*}{ Variables } & \multicolumn{2}{|c|}{$\begin{array}{l}\text { Current smokers } \\
\qquad(\mathrm{n}-1217)\end{array}$} & \multicolumn{2}{|c|}{$\begin{array}{l}\text { Former smokers } \\
\qquad(\text { (n - 1352) }\end{array}$} & \multirow[b]{3}{*}{ p } \\
\hline & \multicolumn{4}{|c|}{ Prevalence of airflow limilation } & \\
\hline & n & $\%(S E)$ & n & $\%($ (SE) & \\
\hline $\mathrm{FEV}_{1} / \mathrm{FVC}<0.7$ & 261 & $19.2(1.34)$ & 322 & $22.1(1.41)$ & 0.114 \\
\hline $\begin{array}{l}\text { Normal } \\
\text { spirometry }\end{array}$ & 956 & $80.8(1.43)$ & 1030 & $77.9(1.41)$ & \\
\hline
\end{tabular}

\begin{tabular}{|c|c|c|c|c|c|}
\hline & \multicolumn{4}{|c|}{ Vean age } & \multirow[b]{2}{*}{ p } \\
\hline & n & Mean SE & n & Vean SE & \\
\hline $\mathrm{FEV}_{1} / \mathrm{FVC}<0.7$ & 261 & $60.98 \pm 0.78$ & 322 & $64.83 \pm 0.82$ & $<0.001$ \\
\hline $\begin{array}{l}\text { Normal } \\
\text { spirometry }\end{array}$ & 956 & $49.13 \pm 0.28$ & 1030 & $53.45 \pm 0.38$ & $<0.001$ \\
\hline Total & 1217 & $51.40 \pm 0.33$ & 1352 & $55.97 \pm 0.40$ & $<0.001$ \\
\hline
\end{tabular}

Prevalence of air flow limitation data are presented as weighted \% (SE), p-value is by chi-squared. Mean age data are presented as weighted mean \pm standard error (SE), p-vales are by Student's t-test.

to their smoking status. The prevalence of airflow limitation among the study participants was $19.2 \%$ and $22.1 \%$ in current and former smokers, respectively. The mean ages of the study participants were 51.40 and 55.97 years among current and former smokers, respectively. The mean age of study participants with airflow limitation was $60.98 \pm 0.78$ and $64.83 \pm 0.82$ years among current and former smokers, respectively. Regardless of smoking history, participants with airflow limitation were older than those with normal spirometry results. In addition, Supplementary Tables 1.1 and 1.2 summarise the prevalence of airflow limitation and mean ages of the entire population for whom spirometry was performed, including nonsmokers.

\section{Sociodemographic characteristics and smoking history}

Table 2 summarises the sociodemographic characteristics of the study participants according to the presence or absence of airflow limitation. The mean age of the group with airflow limitation was significantly higher (62.98 years) than that of the group without airflow limitation (51.17 years; $\mathrm{p}<0.001)$. Furthermore, the prevalence of airflow limitation increased in older populations. The prevalence of airflow limitation in participants between 40 and 55 years of age was the lowest (9.1\%), and the prevalence of airflow limitation in participants
Table 2. Sociodemographic characteristics of study participants according to the presence or absence of airflow limitation $(\mathrm{N}=2569)$

\begin{tabular}{|c|c|c|c|}
\hline Variables & $\begin{array}{l}\text { Group with } \\
\text { airflow } \\
\text { limilation } \\
(\mathbf{n}-\mathbf{5 8 3})\end{array}$ & $\begin{array}{l}\text { Group without } \\
\text { airflow } \\
\text { limilation } \\
\text { (n-1986) }\end{array}$ & p \\
\hline \multirow{2}{*}{$\begin{array}{l}\text { Age (years), } \\
\text { mean } \pm S E\end{array}$} & $62.98 \pm 0.57$ & $51.17 \pm 0.25$ & $<0.001$ \\
\hline & $\%$ (SE) & $\%(\mathrm{SE})$ & p \\
\hline Age group (years) & & & $<0.001$ \\
\hline $40-55$ & $9.1(0.92)$ & $90.9(0.92)$ & \\
\hline $56-65$ & $30.6(2.35)$ & 69.4 (2.35) & \\
\hline $66-75$ & $52.2(3.03)$ & $47.8(3.03)$ & \\
\hline$\geq 76$ & $65.9(5.63)$ & $34.1(5.63)$ & \\
\hline Gender & & & 0.024 \\
\hline Male & $21.3(1.08)$ & $78.8(1.08)$ & \\
\hline Female & $13.8(2.67)$ & $86.2(2.67)$ & \\
\hline Marital status & & & $<0.001$ \\
\hline Married & $20.4(1.05)$ & 79.6 (1.05) & \\
\hline Never-married & $5.6(2.55)$ & $94.4(2.55)$ & \\
\hline $\begin{array}{l}\text { Other (divorced, } \\
\text { separated, } \\
\text { widowed) }\end{array}$ & $29.5(3.82)$ & $70.5(3.82)$ & \\
\hline
\end{tabular}

\begin{tabular}{llll} 
Employment types & & & $<0.001$ \\
Clerical work & $11.5(1.33)$ & $88.5(1.33)$ & \\
Labor work & $20.7(1.44)$ & $79.3(1.44)$ & \\
Unemployed & $37.2(2.59)$ & $62.8(2.59)$ & \\
Living place & & & 0.005 \\
\hline Urban & $18.9(1.08)$ & $81.1(1.08)$ & \\
Rural & $25.5(2.26)$ & $74.5(2.26)$ & \\
Household income & & & \\
(\% in quartiles) & & & \\
1 Lowest & $20.4(1.91)$ & $79.6(1.91)$ & \\
2 & $23.0(1.88)$ & $77.0(1.88)$ & \\
3 & $19.9(2.03)$ & $80.1(2.03)$ & \\
4 Highest & $19.1(2.03)$ & $80.9(2.03)$ &
\end{tabular}

Data are presented as weighted mean \pm Standard error (SE) or weighted $\%( \pm \mathrm{SE}) ;$ T-test or chi-squared test was adopted for continuous or categorical variables, respectively. Income quartiles are age and gender adjusted.

$\geq 76$ years of age was highest $(65.9 \%$; $<<0.001)$. In addition, the prevalence of airflow limitation was significantly higher in male $(p=0.024)$, divorced, separated or widowed $(\mathrm{p}<0.001)$ and unemployed $(\mathrm{p}<0.001)$ participants who resided in rural areas $(p=0.005)$. Household income showed no difference between groups.

Table 3 summarises smoking history of study 
Table 3. Smoking history of study participants according to the presence or absence of airflow limitation $(\mathrm{N}=2569)$

\begin{tabular}{|c|c|c|c|}
\hline \multirow[b]{2}{*}{ Variables } & $\begin{array}{l}\text { Group with } \\
\text { airflow } \\
\text { limitation } \\
\text { (n }-583)\end{array}$ & $\begin{array}{l}\text { Group without } \\
\text { airflow } \\
\text { limitation } \\
\text { (n-1986) }\end{array}$ & \multirow[b]{2}{*}{ p } \\
\hline & $\%(S E)$ & $\%(S E)$ & \\
\hline Smoker types & & & 0.114 \\
\hline Current smokers & $19.2(1.34)$ & $80.8(1.34)$ & \\
\hline Former smokers & $22.1(1.41)$ & $77.9(1.41)$ & \\
\hline Current smoker & & & 0.342 \\
\hline \multicolumn{4}{|l|}{ Cigarettes per day } \\
\hline$<10$ & $23.3(3.26)$ & $76.7(3.26)$ & \\
\hline $10-19$ & $18.1(2.08)$ & $81.9(2.08)$ & \\
\hline$\geq 20$ & $18.7(1.86)$ & $81.3(1.86)$ & \\
\hline Years of smoking & $39.62 \pm 0.79$ & $28.08 \pm 0.31$ & $<0.001$ \\
\hline Pack-years & $31.80 \pm 1.37$ & $23.84 \pm 0.58$ & $<0.001$ \\
\hline Former smoker & & & 0.063 \\
\hline \multicolumn{4}{|l|}{ Cigarettes per day } \\
\hline$<10$ & $19.8(3.60)$ & $80.2(3.60)$ & \\
\hline $10-19$ & $17.8(2.36)$ & $82.2(2.36)$ & \\
\hline$\geq 20$ & $25.2(1.93)$ & $74.8(1.93)$ & \\
\hline Years of smoking & $26.81 \pm 1.00$ & $18.64 \pm 0.42$ & $<0.001$ \\
\hline Pack-years & $27.94 \pm 1.44$ & $18.47 \pm 0.66$ & $<0.001$ \\
\hline \multirow{2}{*}{$\begin{array}{l}\text { Years of smoking } \\
\text { cessation }\end{array}$} & $17.37 \pm 1.01$ & $14.55 \pm 0.37$ & 0.009 \\
\hline & & & 0.767 \\
\hline$<1$ & $27.3(8.34)$ & $72.7(8.34)$ & \\
\hline $1 \leq$ duration $<10$ & $21.2(2.57)$ & $78.8(2.57)$ & \\
\hline$\geq 10$ & $22.0(1.84)$ & $78.0(1.84)$ & \\
\hline
\end{tabular}

Data are presented as weighted mean \pm standard error (SE) or weighted $\%( \pm \mathrm{SE}) ;$ T-test or chi-squared test was adopted for continuous or categorical variables, respectively. Income quartiles are age and gender adjusted. participants according to the presence or absence of airflow limitation. The daily smoking amount also did not show a significant difference between two groups; however, there was a significant difference between groups in regard to years of smoking, leading to a significantly higher pack-years in the group with airflow limitation compared with the group without airflow limitation $(\mathrm{p}<0.001)$.

\section{Health behaviours, mental health, nutritional status and medical comorbidities}

Table 4 summarises comorbidities, health behaviours and mental health status of study participants according to the presence or absence of airflow limitation. All of the nutritional indices measured were significantly worse in the group with airflow limitation. The group with airflow limitation had more participants with comorbidities including DM, hypertension, CVD and cancers compared with the group without airflow limitation. Based on the EuroQoL surveys, HRQoL was significantly worse in the group with airflow limitation.

\section{Lifetime smoking amount and severity of airflow limitation}

To address the relationship between severity of airflow limitation and total lifetime smoking amount, a Pearson's correlation analysis was performed between per cent predicted values of $\mathrm{FEV}_{1}$ and total lifetime smoking amount with no significant correlation between the two, among both current and former smokers (Figures 2 and 3).

Table 4. Comparison of health behaviors, mental health, and medical conditions between group with or without airflow limitation

\begin{tabular}{|c|c|c|c|c|c|}
\hline \multirow[b]{2}{*}{ Variables } & \multicolumn{2}{|c|}{ Group with airflow limitation } & \multicolumn{2}{|c|}{ Group without airflow limitation } & \multirow[b]{2}{*}{ p } \\
\hline & n & $\begin{array}{c}\text { Vean SE or weighted "o } \\
\text { SE }\end{array}$ & n & $\begin{array}{c}\text { Vean SE or weighted \% } \\
\text { SE }\end{array}$ & \\
\hline $\mathrm{SBP}(\mathrm{mmHg})$ & 583 & $126.35 \pm 0.89$ & 1984 & $120.85 \pm 0.46$ & $<0.001$ \\
\hline $\mathrm{DBP}(\mathrm{mmHg})$ & 583 & $77.31 \pm 0.58$ & 1984 & $79.76 \pm 0.34$ & $<0.001$ \\
\hline BMI $\left(\mathrm{kg} / \mathrm{m}^{2}\right)$ & 583 & $23.72 \pm 0.16$ & 1086 & $24.42 \pm 0.07$ & $<0.001$ \\
\hline 25(OH)D (ng/mL) & 559 & $19.51 \pm 0.36$ & 1944 & $19.24 \pm 0.22$ & 0.467 \\
\hline \multicolumn{6}{|l|}{ Dietary Intake } \\
\hline (Kcal/day) & 529 & $2136.66 \pm 50.86$ & 1686 & $2428.38 \pm 29.26$ & $<0.001$ \\
\hline Protein (g/day) & 529 & $73.90 \pm 2.54$ & 1686 & $86.09 \pm 1.25$ & $<0.001$ \\
\hline Fat (g/day) & 529 & $34.23 \pm 1.47$ & 1686 & $47.15 \pm 0.99$ & $<0.001$ \\
\hline Carbohydrate (g/day) & 529 & $347.94 \pm 8.24$ & 1686 & 369. $60 \pm 4.59$ & 0.019 \\
\hline Vitamin A (ugRE) & 529 & $854.73 \pm 60.73$ & 1686 & $1008.99 \pm 39.85$ & 0.031 \\
\hline
\end{tabular}


Table 4. Continued

\begin{tabular}{|c|c|c|c|c|c|}
\hline \multirow[b]{2}{*}{ Variables } & \multicolumn{2}{|c|}{ Group with airflow limitation } & \multicolumn{2}{|c|}{ Group without airflow limitation } & \multirow[b]{2}{*}{ p } \\
\hline & n & $\begin{array}{c}\text { Vean SE or weighted \% } \\
\text { SE }\end{array}$ & n & $\begin{array}{c}\text { Mean SE or weighted \% } \\
\text { SE }\end{array}$ & \\
\hline Vitamin B1 (mg) & 529 & $1.31 \pm 0.04$ & 1686 & $1.61 \pm 0.03$ & $<0.001$ \\
\hline Vitamin B2 (mg) & 529 & $1.19 \pm 0.04$ & 1686 & $1.44 \pm 0.02$ & $<0.001$ \\
\hline Vitamin C (mg) & 529 & $98.56 \pm 4.01$ & 1686 & $122.58 \pm 2.63$ & $<0.001$ \\
\hline Total cholesterol (mg/dL) & 559 & $187.25 \pm 2.21$ & 1944 & $194.57 \pm 1.04$ & 0.002 \\
\hline Diabetes mellitus (\%) & 544 & 18.57 & 1895 & 12.34 & $<0.001$ \\
\hline Hypertension (\%) & 582 & 49.31 & 1978 & 35.69 & $<0.001$ \\
\hline CVD (\%) & 583 & 6.00 & 1986 & 4.08 & $<0.001$ \\
\hline${ }^{*}$ Cancer $(\%)$ & 583 & 4.97 & 1984 & 2.87 & 0.003 \\
\hline Heavy drinker (\%) & 437 & 18.99 & 1702 & 28.43 & 0.006 \\
\hline Regular exerciser (\%) & 583 & 9.26 & 1985 & 10.48 & 0.997 \\
\hline Perceived health status (\%) & 582 & & 1984 & & $<0.001$ \\
\hline Very good/good & & 34.53 & & 36.39 & \\
\hline Fair & & 44.50 & & 49.70 & \\
\hline Poor/very poor & & 20.96 & & 13.91 & \\
\hline$E Q-5 D$ & 582 & $0.92 \pm 0.01$ & 1984 & $0.96 \pm 0.00$ & $<0.001$ \\
\hline Euro0oL:VAS & 582 & $71.28 \pm 1.08$ & 1982 & $75.32 \pm 0.45$ & $<0.001$ \\
\hline $\begin{array}{l}\text { Perceived psychological stress } \\
\text { (\% for yes) }\end{array}$ & 583 & 15.09 & 1986 & 24.62 & $<0.001$ \\
\hline Depressive symptom (\%) & 583 & 9.78 & 1986 & 10.67 & 0.681 \\
\hline Suicide ideation (\%) & 583 & 21.0 & 1986 & 79.0 & 0.316 \\
\hline
\end{tabular}

Data except comorbidity data are presented as subject number $(\mathrm{n})$, weighted mean \pm standard error $( \pm \mathrm{SE}$ ) or weighted $\%$ ( $\pm \mathrm{SE}$ ); T-test or chi-squared test was adopted for continuous or categorical variables, respectively. ${ }^{*}$ The patients with lung cancer were excluded among cancer patients. SBP: systolic blood pressure, DBP: diastolic blood pressure, BMI: body mass index, CVD: cardiovascular disease.

Figure 2. Pearson's correlation analysis between per cent predicted values of $\mathrm{FEV}_{1}$ and total amount of lifetime smoking among current smokers

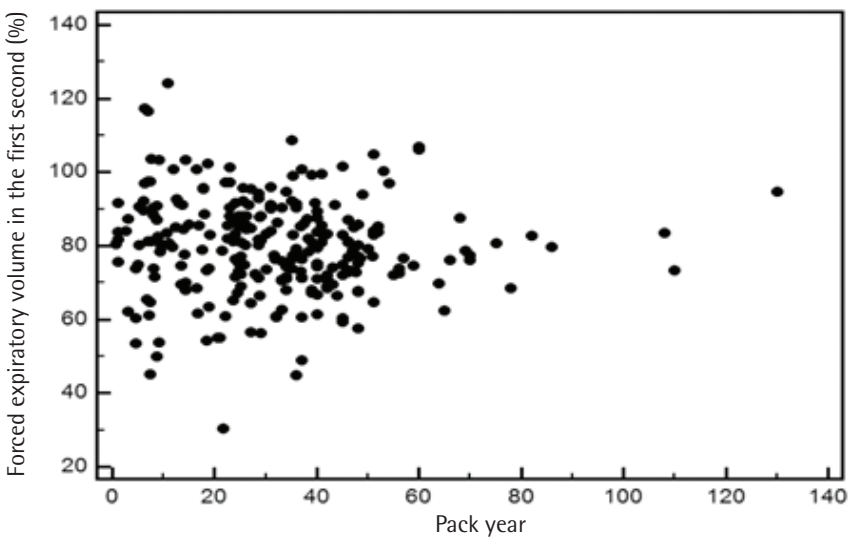

Factors associated with the development of airflow limitation among smokers

Table 5 and Supplementary Table 2 summarise the factors associated with the development of airflow limitation. Age, male gender and lifetime smoking
Figure 3. Pearson's correlation analysis between per cent predicted values of FEV , and total amount of lifetime smoking among former smokers

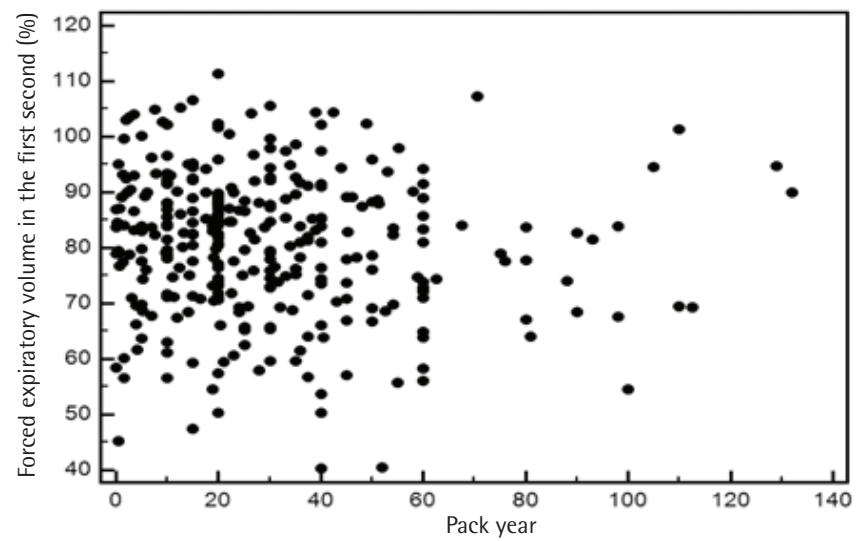

amount were significantly associated with the development of airflow limitation after controlling for sociodemographic, nutritional and various healthrelated conditions. Smokers aged 56-65 years, $66-75$ years and $\geq 76$ years were $2.32,4.33$ and 
Table 5. Factors associated with the development of airflow limitation among study participants

\begin{tabular}{|c|c|c|}
\hline Factors & Adjusted OR $\left(95^{\circ} \% \text { CI }\right)^{\mathrm{a}}$ & p \\
\hline \multicolumn{3}{|c|}{ Age (ref: 40-55 years) } \\
\hline $56-65$ & $2.32(1.54-3.50)$ & $<0.001$ \\
\hline $66-75$ & $4.33(2.47-7.60)$ & $<0.001$ \\
\hline$\geq 76$ & $9.74(3.61-26.27)$ & $<0.001$ \\
\hline \multicolumn{3}{|c|}{ Gender (ref: Female) } \\
\hline Male & $3.30(1.38-6.68)$ & 0.006 \\
\hline \multicolumn{3}{|c|}{ Lifetime smoking amount } \\
\hline (pack-years) & $1.02(1.01-1.03)$ & $<0.001$ \\
\hline
\end{tabular}

Multiple logistic regression analyses, OR: odds ratio, $\mathrm{Cl}$ : confidential interval. a Adjusted for age, gender, marital status, employment types, living place, lifetime smoking amount, BMI, dietary intake, comorbidities such as DM, hypertension, CVD, cancer, and heavy drinking, perceived health status, EQ-5D, EuroQoL:VAS, and perceived stress

9.74 times, respectively, more likely to have airflow limitation than smokers between 40 and 55 years of age (95\% CI: $1.54-3.50 ; 2.47-7.60$; and 3.61-26.27, respectively). Male smokers were 3.03 (95\% CI: $1.38-$ 6.68) times more likely to have airflow limitation than female smokers. In terms of lifetime smoking history, an increase of one pack-year corresponded to a 1.02 (95\% CI: 1.01-1.03) times higher chance of developing airflow limitation.

\section{DISCUSSION}

The present study investigated the prevalence of airflow limitation, suggestive of having COPD, among smokers, factors associated with airflow limitation among smokers and the relationship between smoking history and the severity of airflow limitation among Korean smokers using the nationally representative cross-sectional survey data publicly available through KNHANES (http://knhanes.cdc.go.kr). Most studies exploring risk factors for COPD have compared smokers and non-smokers, with smoking as only one of the independent variables ${ }^{26,29}$. In this study, we took a different approach, studying only smokers and comparing those with or without airflow limitation. We believe that such a simplified approach would give us a clearer answer regarding why only some smokers develop COPD. Airflow limitation that is only partially reversible with a bronchodilator or is completely irreversible is the characteristic physiological feature of COPD ${ }^{33,36}$. Given the lack of the data of post-bronchodilator $\mathrm{FEV}_{1}$ in this study, we adopted the term 'airflow limitation' instead of COPD in the present study. The principal findings of this study will be summarised next.

First, the prevalence of airflow limitation among smokers in the present study was approximately $20 \%$ (Table 1), which is comparable with rates previously published in cross-sectional studies similar to ours ${ }^{8}$. As mentioned earlier, previous researchers have reported that COPD risk varies according to ethnicity ${ }^{24,25}$. For instance, COPD has a higher prevalence in White than in non-White ethnicities ${ }^{24,25}$. Possible reasons proposed for such ethnic differences include variable pathways for nicotine metabolism or differences in dietary intake of fruit and vegetables, among others $^{38,39}$. Nonetheless, the prevalence of airflow limitation among smokers in the present study was comparable with rates previously observed ${ }^{40}$.

Second, among the many variables we examined, only age, male gender and lifetime smoking amount were significantly associated with the development of airflow limitation (Table 5 and Supplementary Table $2)$. This indicates that an older Korean man who is a heavy smoker is more likely to develop COPD. The importance of aging in the pathogenesis of COPD has been suggested by others ${ }^{12}$. For example, the incidence of COPD increases with age, with the greatest increase observed in patients aged $65-74$ years ${ }^{11}$. Normal aging results in the loss of elastic recoil, stiffening of the chest wall, gas exchange alteration, and decrease in exercise tolerance. These changes are similar to those in patients with emphysema. Thus, aging is considered to be a significant contributor to the development of COPD ${ }^{12}$. Next, a significant association between lifetime smoking amount and airflow limitation was observed, and the prevalence of airflow limitation was significantly higher in male smokers in this study. Although COPD is believed to be more common in men, some researchers suggest that women are actually more susceptible to tobacco-induced lung diseases ${ }^{13,14}$. Because of increased tobacco use among women in high-income countries and the higher risk for exposure to indoor air pollution (such as solid fuel used for cooking and heating) in low-income countries, the disease now appears to affect men and women almost equally ${ }^{41}$.

Third, we examined the relationship between packyears and the severity of airflow limitation. Although we observed a significant association between packyears and the prevalence of airflow limitation, oddly, 
the severity of airflow limitation did not have a significant correlation with pack-years in our study (Figures 2 and 3). According to a recent study, the single best variable for predicting COPD development is a $>40$ pack-year history of smoking ${ }^{42}$. However, a threshold for daily smoking amount and years of smoking resulting in COPD may vary from one individual to another ${ }^{9}$. Of note, a positive relationship between pack-years and the prevalence of airflow limitation in this study appears not to be due to daily smoking amount but due to years of smoking, as suggested in Table 3. Intriguingly, a recent study has reported that 'years of smoking' alone provides risk estimates of $\mathrm{COPD}^{43}$. Most studies use pack-years to assess the lifetime smoking amount, but the pack-years value is a measure that assigns the same weight on both daily smoking amount and years of smoking. The Lung Health Study, which included participants from diverse ethnic backgrounds, reported that increasing daily smoking amount is associated with rapidly declining lung function in mild-to-moderate COPD; however, no direct comparisons were made between daily smoking amount and years of smoking ${ }^{44}$. Another cross-sectional study using the COPDGene cohort of current and former smokers with non-Hispanic White or African-American ethnic background showed that 'years of smoking' was a more important factor in the development of COPD ${ }^{43}$. Therefore, it would be interesting to identify which factor-daily smoking amount, years of smoking or lifetime smoking amount (pack-years) - is most responsible in the development of COPD according to ethnicity in future studies.

Other findings of our study are also worth mentioning. Although they did not turn out to be significant factors after controlling for multiple variables, most nutritional indices, comorbidities and quality of life were significantly worse in the airflow limitation group when a simple comparison was made (Table 4). Nutritional deficiency in COPD may result from an imbalance between energy intake and consumption. Inadequate intake has been explained by impaired regulation of leptin, a hormone that reduces food intake, in the setting of chronic dyspnoea. The increased energy consumption may be due to the increased work expanded in breathing or increased protein catabolism due to systemic inflammation ${ }^{45}$. Paradoxically, the prevalence of metabolic syndrome is also high in $\mathrm{COPD}^{22}$. A recent meta-analysis has shown that healthy diet characterised by high intake of vegetables, fruit, fish and whole-grain products was associated with a decreased risk of COPD, while an unhealthy diet characterised by all kinds of red and processed meats, refined grains, sweets and French fries was associated with an increased risk of $\mathrm{COPD}^{21}$. Therefore, it seems that both nutritional deficiency and excess intake, as well as dietary patterns, which could be related to geographical differences, seem to be associated with the development of COPD. It is not clear whether ethnicity plays a different role in the development of COPD according to the nutritional status. Nonetheless, we did not find nutrition a significant factor in the development of airflow limitation among Korean smokers (Tables 4 and 5). COPD is often accompanied by comorbidities, such as cardiovascular disease, metabolic syndrome, DM and gastro-oesophageal reflux ${ }^{46}$. These comorbidities are associated with frequent exacerbation of COPD and increased mortality associated with $\mathrm{COPD}^{47-50}$. Although the prevalences of DM, hypertension, CVD and cancers were higher in the group with airflow limitation, we did not find comorbidity as a significant factor in the development of airflow limitation among our study participants (Tables 4 and 5). Also, the level of household income showed no difference between the group without airflow limitation and the group with airflow limitation, suggesting that socioeconomic status might not be a critical factor in the development of airflow limitation among Korean smokers, contrary to what has been previously reported ${ }^{19}$.

In the past, previous researchers have reported that various factors, such as aging ${ }^{11,12}$, gender ${ }^{13,14}$, abnormal lung growth and development ${ }^{5}$, occupational exposure to particles ${ }^{15}$, air pollution ${ }^{16}$, lower socioeconomic status $^{19,20}$, nutrition ${ }^{21}$, obesity ${ }^{22}$ and educational level ${ }^{23}$, were associated with the development of COPD among smokers. In addition, a few studies have examined the factors associated with COPD according to ethnicity or country, and the identified risks were more or less the same as reported herein ${ }^{17,18,26-29}$. However, the effect of air pollution, biomass smoke or chronic respiratory infection such as tuberculosis, often revealed different factors depending on the geographical location ${ }^{17,18,26-29}$. Notably, one study investigated the factors of airflow limitation using the same cohort of KNHANES. Unlike our study, it analysed the prevalence of airflow limitation and the 
factors associated with airflow limitation in the entire population, including non-smokers. The prevalence of airflow limitation in that study was understandably lower than that reported by us owing to the inclusion of non-smokers in the analysis. The study reported that age, smoking amounts, male gender and having asthma or tuberculosis were associated with higher prevalence of airflow limitation. Further, obesity and higher educational levels were associated with lower prevalence of airflow limitation ${ }^{23}$. Considering that we applied stricter inclusion and exclusion criteria to select the study participants and our data were derived from only smokers, it will be difficult to make a direct comparison between the two studies. However, the other study also reported age, smoking amount and male gender as critical factors associated with the development of COPD among Korean smokers.

\section{Limitations}

Our study has some limitations. To diagnose COPD definitively, post-bronchodilator spirometry data are needed to exclude patients with reversible airflow limitation, such as those with asthma. Unfortunately, the KNHANES data do not include post-bronchodilator spirometry results. However, we believe that most patients with airflow limitation in our study had COPD for the following reasons: we excluded patients with a history of asthma; all those included were smokers; and those with other pulmonary diseases apparent on CXR were excluded. Therefore, we believe that our findings are reliable even without post-bronchodilator spirometry data. However, we recognise that some patients with asthma or asthma COPD overlap (ACO) might have been included. In addition, we could not analyse the effect of medication that the participants were taking as some, such as beta blockers, could influence airflow limitation; furthermore, we could not take into account the effect of exposure to air pollution, occupational hazards and the inhalation of biomass fuel or particles, which are all established factors associated with COPD, due to a lack of detailed information ${ }^{15,16}$.

\section{CONCLUSIONS}

We conducted the present study to identify the factors that make a 'susceptible smoker' develop airflow limitation, suggestive of having COPD, among smokers in Korea. We did this using a nationally representative cross-sectional survey by comparing smokers with and without airflow limitation. After controlling for multiple variables, we found that age, male sex and pack-years were the only factors significantly associated with the development of airflow limitation. This study also suggests that among Korean smokers, years of smoking may be a more important factor associated with airflow limitation than daily smoking amount. Our study findings indicate that the best way to prevent the development and progress of COPD is smoking cessation.

\section{REFERENCES}

1. Adeloye D, Chua S, Lee C, et al. Global and regional estimates of COPD prevalence: Systematic review and meta-analysis. J Glob Health. 2015;5(2):020415. doi:10.7189/jogh.05.020415

2. Mathers CD, Loncar D. Projections of global mortality and burden of disease from 2002 to 2030. PLoS Med. 2006;3(11):e442. doi:10.1371/journal.pmed.0030442

3. Global Burden of Disease Study 2013 Collaborators. Global, regional, and national incidence, prevalence, and years lived with disability for 301 acute and chronic diseases and injuries in 188 countries, 19902013: a systematic analysis for the Global Burden of Disease Study 2013. Lancet. 2015;386(9995):743-800. doi:10.1016/S0140-6736(15)60692-4

4. Salvi SS, Barnes PJ. Chronic obstructive pulmonary disease in non-smokers. Lancet. 2009;374(9691):733743. doi:10.1016/s0140-6736(09)61303-9

5. McGeachie MJ, Yates KP, Zhou X, et al. Patterns of Growth and Decline in Lung Function in Persistent Childhood Asthma. N Engl J Med. 2016;374(19):18421852. doi:10.1056/NEJMoa1513737

6. Hu G, Zhou Y, Tian J, et al. Risk of COPD from exposure to biomass smoke: a metaanalysis. Chest. 2010;138(1):2031. doi:10.1378/chest.08-2114

7. Rennard S, Dectamer M, Calverley PMA, et al. Impact of COPD in North America and Europe in 2000: subjects' perspective of Confronting COPD International Survey. Eur Respir J. 2002;20(4):799-805. doi:10.1183/09031936.02.03242002

8. Fletcher C, Peto R, Tinker C, Frank ES. The natural history of chronic bronchitis and emphysema. Oxford: Oxford University Press; 1976.

9. Rennard SI, Vestbo J. COPD: the dangerous underestimate of 15\%. Lancet. 2006;367(9518):12161219. doi:10.1016/s0140-6736(06)68516-4

10. Lundback B, Lindberg A, Lindstrom M, et al. Not 15 but $50 \%$ of smokers develop COPD?-Report from the Obstructive Lung Disease in Northern Sweden Studies. Respir Med. 2003;97(2):115-122. doi:10.1053/rmed.2003.1446 
11. Mannino DM, Homa DM, Akinbami LJ, Ford ES, Redd SC. Chronic obstructive pulmonary disease surveillance-United States, 1971-2000. MMWR Surveill Summ. 2002;51(6):1-16. https://www.cdc.gov/mmwr/preview/ mmwrhtml/ss5106a1.htm. Accessed October 31, 2018.

12. Ito K, Barnes PJ. COPD as a disease of accelerated lung aging. Chest. 2009;135(1):173-180. doi:10.1378/chest.08-1419

13. Sørheim IC, Johannessen A, Gulsvik A, Bakke PS, Silverman EK, DeMeo DL. Gender differences in COPD: are women more susceptible to smoking effects than men? Thorax. 2010;65(6):480-485. doi:10.1136/thx.2009.122002

14. Raghavan D, Varkey A, Bartter T. Chronic obstructive pulmonary disease: the impact of gender. Curr Opin Pulm Med. 2017;23(2):117-123. doi:10.1097/MCP.0000000000000353

15. Eisner MD, Anthonisen N, Coultas D, et al. An official American Thoracic Society public policy statement: Novel risk factors and the global burden of chronic obstructive pulmonary disease. Am J Respir Crit Care Med. 2010;182(5):693-718. doi:10.1164/rccm.200811-1757st

16. Liu S, Zhou Y, Liu S, et al. Association between exposure to ambient particulate matter and chronic obstructive pulmonary disease: results from a crosssectional study in China. Thorax. 2017;72(9):788-795. doi:10.1136/thoraxjnl-2016-208910

17. Magitta NF, Walker RW, Apte KK, et al. Prevalence, risk factors and clinical correlates of COPD in a rural setting in Tanzania. Eur Respir J. 2018;51(2):1700182. doi:10.1183/13993003.00182-2017

18. Jaganath D, Miranda JJ, Gilman RH, et al. Prevalence of chronic obstructive pulmonary disease and variation in risk factors across four geographically diverse resourcelimited settings in Peru. Respir Res. 2015;16:40. doi:10.1186/s12931-015-0198-2

19. Kanervisto M, Vasankari T, Laitinen T, Heliövaara M, Jousilahti P, Saarelainen S. Low socioeconomic status is associated with chronic obstructive airway diseases. Respir Med. 2011;105(8):1140-1146. doi:10.1016/j.rmed.2011.03.008

20. Gershon AS, Hwee J, Victor JC, Wilton AS, To T. Trends in socioeconomic status-related differences in mortality among people with chronic obstructive pulmonary disease. Ann Am Thorac Soc. 2014;11(8):1195-1202. doi:10.1513/annalsats.201403-094oc

21. Zheng PF, Shu L, Si CJ, Zhang XY, Yu XL, Gao W. Dietary Patterns and Chronic Obstructive Pulmonary Disease: A Meta-analysis. COPD. 2016;13(4):515-522. doi:10.3109/15412555.2015.1098606

22. Cebron Lipovec N, Beijers RJ, van den Borst B, Doehner W, Lainscak M, Schols AM. The Prevalence of Metabolic Syndrome In Chronic Obstructive Pulmonary Disease: A Systematic Review. COPD. 2016;13(3):399-406. doi:10.3109/15412555.2016.1140732
23. Park H, Jung SY, Lee K, et al. Prevalence of chronic obstructive lung disease in Korea using data from the fifth Korea national health and nutrition examination survey. Korean J Fam Med. 2015;36(3):128-134. doi:10.4082/kjfm.2015.36.3.128

24. Gilkes A, Ashworth M, Schofield P, et al. Does COPD risk vary by ethnicity? A retrospective cross-sectional study. Int J Chron Obstruct Pulmon Dis. 2016;11:739-746. doi:10.2147/copd.s96391

25. Martin A, Badrick E, Mathur R, Hull S. Effect of ethnicity on the prevalence, severity, and management of COPD in general practice. Br J Gen Pract. 2012;62(595):e76-81. doi:10.3399/bjgp12x625120

26. Yang Y, Mao J, Ye Z, Li J, Zhao H, Liu Y. Risk factors of chronic obstructive pulmonary disease among adults in Chinese mainland: A systematic review and meta-analysis. Respir Med. 2017;131:158-165. doi:10.1016/j.rmed.2017.08.018

27. Al Ghobain M, Alhamad EH, Alorainy HS, Al Kassimi F, Lababidi H, Al-Hajjaj MS. The prevalence of chronic obstructive pulmonary disease in Riyadh, Saudi Arabia: a BOLD study. Int J Tuberc Lung Dis. 2015;19(10):12521257. doi:10.5588/ijtld.14.0939

28. Chen Y, Breithaupt K, Muhajarine N. Occurrence of chronic obstructive pulmonary disease among Canadians and sexrelated risk factors. J Clin Epidemiol. 2000;53(7):755761. doi:10.1016/s0895-4356(99)00211-5

29. Garcia Rodriguez LA, Wallander MA, Tolosa LB, Johansson S. Chronic obstructive pulmonary disease in UK primary care: incidence and risk factors. COPD. 2009;6(5):369-379. doi:10.1080/15412550903156325

30. Korea Centers for Disease Control and Prevention. The work-shop report and guide to the utilization of the data from the Korea National Health and Nutrition Examination Survey. https://knhanes.cdc.go.kr/knhanes/ index.do. Accessed May 14, 2017.

31. Centers for Disease Contorl and Prevention. National Health Interview Survey. https://www.cdc.gov/nchs/ nhis/tobacco/tobacco_glossary.htm. Accessed October $31,2018$.

32. Bondy SJ, Victor JC, Diemert LM. Origin and use of the 100 cigarette criterion in tobacco surveys. Tob Control. 2009;18(4):317-223. doi:10.1136/tc.2008.027276

33. Vestbo J, Hurd SS, Agustí AG, et al. Global strategy for the diagnosis, management, and prevention of chronic obstructive pulmonary disease: GOLD executive summary. Am J Respir Crit Care Med. 2013;187(4):347365. doi:10.1164/rccm.201204-0596pp

34. Miller MR, Hankinson J, Brusasco V, et al. Standardisation of spirometry. Eur Respir J. 2005;26(2):319-338. doi:10.1183/09031936.05.00034805

35. Choi JK, Paek D, Lee JO. Normal predictive values of spirometry in Korean population. Tuberc Respir Dis. 2005;58:230-242. doi:10.4046/trd.2005.58.3.230

36. Celli BR, MacNee W, Agusti A, et al. Standards for the 
diagnosis and treatment of patients with COPD: a summary of the ATS/ERS position paper. Eur Respir J. 2004;23(6):932946. doi:10.1183/09031936.04.00014304

37. EuroQol Group. EuroQol--a new facility for the measurement of health-related quality of life. Health Policy. 1990;16(3):199-208. doi:10.1016/0168-8510(90)90421-9

38. Pérez-Stable EJ, Herrera B, Jacob III P, Benowitz NL. Nicotine metabolism and intake in black and white smokers. JAMA. 1998;280(2):152-156. doi:10.1001/jama.280.2.152

39. Smith-Warner SA, Spiegelman D, Yaun SS, et al. Fruits, vegetables and lung cancer: a pooled analysis of cohort studies. Int J Cancer. 2003;107(6):1001-1011. doi:10.1002/ijc.11490

40. Fletcher C, Peto R. The natural history of chronic airflow obstruction. Br Med J. 1977;1(6077):1645-1648. doi:10.1136/bmj.1.6077.1645

41. Ford ES, Croft JB, Mannino DM, Wheaton AG, Zhang X, Giles WH. COPD surveillance--United States, 1999-2011. Chest. 2013;144(1):284-305. doi:10.1378/chest.13-0809

42. Qaseem A, Wilt TJ, Weinberger SE, et al. Diagnosis and management of stable chronic obstructive pulmonary disease: a clinical practice guideline update from the American College of Physicians, American College of Chest Physicians, American Thoracic Society, and European Respiratory Society. Ann Intern Med. 2011;155(3):179-191. doi:10.7326/0003-4819-155-3-201108020-00008

43. Bhatt SP, Kim YI, Harrington KF, et al. Smoking duration alone provides stronger risk estimates of chronic obstructive pulmonary disease than pack-years. Thorax. 2018;73(5):414-421. doi:10.1136/thoraxjnl-2017-210722

44. Scanlon PD, Connett JE, Waller LA, et al. Smoking cessation and lung function in mild-to-moderate chronic obstructive pulmonary disease. The Lung Health Study. Am J Respir Crit Care Med. 2000;161(2):381-390. doi:10.1164/ajrccm.161.2.9901044

45. Wagner PD. Possible mechanisms underlying the development of cachexia in COPD. Eur Respir J. 2008;31(3):492-501. doi:10.1183/09031936.00074807

46. Vanfleteren LE, Spruit MA, Groenen M, et al. Clusters of comorbidities based on validated objective measurements and systemic inflammation in patients with chronic obstructive pulmonary disease. Am J Respir Crit Care Med. 2013;187(7):728-735. doi:10.1164/rccm.201209-1665oc

47. Viniol C, Vogelmeier CF. Exacerbations of COPD. Eur Respir Rev. 2018;27(147):170103. doi:10.1183/16000617.0103-2017

48. Westerik JA, Metting EI, van Boven JF, Tiersma W, Kocks JW, Schermer TR. Associations between chronic comorbidity and exacerbation risk in primary care patients with COPD. Respir Res. 2017;18(1):31. doi:10.1186/s12931-017-0512-2

49. Sin DD, Anthonisen NR, Soriano JB, Agusti
AG. Mortality in COPD: Role of comorbidities. Eur Respir J. 2006;28(6):1245-1257. doi:10.1183/09031936.00133805

50. Divo M, Cote C, de Torres JP, et al. Comorbidities and risk of mortality in patients with chronic obstructive pulmonary disease. Am J Respir Crit Care Med. 2012;186(2):155-161. doi:10.1164/rccm.201201-0034oc

ACKNOWLEDGEMENTS

We are grateful to the Korea Centres for Disease Control and Prevention for allowing us to use the Korea National Health and Nutrition Examination Survey (KNHANES) data.

\section{CONFLICTS OF INTEREST}

Authors have completed and submitted the ICMJE Form for Disclosure of Potential Conflicts of Interest and none was reported.

\section{FUNDING}

There was no source of funding for this research.

\section{AUTHORS' CONTRIBUTIONS}

Author contributions involved conceptualization by WKC; methodology by $Y K$; formal analysis by $Y K$; investigation by $Y K$ and WKC; data curation by $Y K$ and WKC; original draft preparation by $Y K$; writing, review and editing by WKC; and supervision by WKC.

\section{PROVENANCE AND PEER REVIEW}

Not commissioned; externally peer reviewed. 